\title{
Measures of relationships and association among body weight and biometric traits of
} donkeys in Northwest Nigeria

${ }^{1}$ John, P. A. and ${ }^{2}$ Iyiola-Tunji, A. O.

${ }^{\prime}$ Department of Animal Science, Ahmadu Bello University, Zaria, Nigeria

${ }^{2}$ National Agricultural Extension and Research Liaison Services, Ahmadu Bello University, Zaria, Nigeria

*Corresponding author: Email: johnpaulapagu@gmail.com, +2348136566374

\section{Abstract}

Body linear measurements of different age categories of donkeys were used to predict the body weight of donkeys using stepwise regression procedure. This work was conducted to estimates the live body weight of donkeys from biometric traits. A total of 700 donkeys were measured into three age groups (weaners 6 months- 1 year, young above 1 - 3 years and adults 3 years and above). Morphometric measures taken were body weight, head length, head width, ear length, neck length, neck circumference, shoulder width, height at withers, heart girth, body length and tail length using random sampling technique. Significant variations were observed in morphometric $(P<0.05, P<0.01)$ traits. The results of the study showed that significantly $(P<0.01)$ predicted body weight of these donkeys with good efficiencies were neck circumference (NC), tail length (TL) and body length (BL) were the best predictors of body weight with $R^{2}=100 \%$ in weaners, head width (HWD), neck circumference (NL), neck circumference (NC) and height at withers $(H W)$ with $R^{2}=100 \%$ in young and $H W, H G$ with $R^{2}=100 \%$ in adult category. The traits were significantly $(p<0.05$, $0.01)$ and positively correlated amongst themselves $(r=0.09-0.87)$.It is therefore concluded that the inclusion of two variables improved the prediction marginally, but the addition of further variables gave little further improvement. The association may be useful as selection criterion, since positive correlations of traits suggest that the traits are under the same gene action (pleiotropy/linkage). It is therefore recommended that tail length, neck circumference, body length, height at withers and heart girth should be used as the best predictors of body weight across the sex and age categories of donkeys.

Keywords: Association, Biometric traits, Body weight, donkey, Nigeria, Relationships.

\section{Introduction}

Morphometric traits related to body lengths, heights and girths of live animals were measured to assess the relationship between these variables and the live weight for breed characterization in different animal species: in cattle (Mekonnen and Biruk, 2004), in sheep (Oke and Ogbonnaya, 2011) or goat (Adeyinka and Mohammed, 2006; Fajemilehin and Salako, 2008) and in donkeys (John et al., 2017). Determining animal live body weight, linear body measurements, and their inter-relationship and correlation is imperative for determining genetic potential, breed standards, and improved breeding programs for higher meat production (Younas et al., 2013). The phenotypic variability in metric measurements as much as performance traits in livestock production are affected by both genetic and environmental factors (Semakula et al., 2011). Live weight of an animal is important in determining the potential to carryout prescribed draft tasks (Bartholomew et al., 1993). Proper management of donkeys requires the ability to match the animals' live weight to draft tasks required. However, most smallholder farmers have no access to livestock scale. A reliable and practical method of estimating live weight is also useful when dosing 
animals with medicine, in the assessment of the impact of nutritional and veterinary interventions on donkeys and in determining recommendations for load carrying (Pearson and Ouassat, 1996). The biometric traits of donkeys also help in determining the live weight of donkeys based on sex and age categories. Unfortunately, the knowledge and information on prediction equation for donkeys in Nigeria are seldom available where donkeys are kept for work. Therefore, the estimation of live weight, making use of biometric traits could be used as an alternative to direct weighing. Eley and French (1993) each developed a prediction equation for donkeys, because they found that the methods used to estimate the live weight of horses were inappropriate. Therefore, there is a need to establish simple and practical methods of estimating live weight of donkeys from simple body dimensions. The prediction equation containing two or more variables gave a reasonable degree of prediction (Pearson and Oussat, 1996) than an equation with one variable. The objective of the present study is, therefore, to estimates the live weight and relationships among biometric traits of donkey through body dimension measures based on sex and age categories using correlation analysis and stepwise regression approach which will help to develop an equation that will substitute the use of weighing scale.

\section{Materials and methods Study area}

The study was conducted in the semi-arid zone of Nigeria in Sokoto, Jigawa, Kano, Katsina, Kaduna, Zamfara and Kebbi States respectively. The semi-arid zone of Nigeria starts from about $11^{\circ} \mathrm{N}$ latitude and ends at the Nigeria-Niger frontier. It encompasses the Sudan and Sahel Savanna and part of the Northern Guinea Savanna. The mean annual temperature runs between 26 and $28^{\circ} \mathrm{C}$. There is a single rainy season from May to October, with mean annual rainfall ranging from $1016 \mathrm{~mm}$ in the wettest parts to less than $508 \mathrm{~mm}$ in the driest parts. The length of growing period is about 100-150 days which makes it possible to cultivate a wide variety of crops (Ogungbile et al., 1998). The semi-arid zone has a land mass of $113,530 \mathrm{~km}^{2}$ and a population of over 35 million people (NPC, 2006). This part of Nigeria has very low level of infrastructure and roads which render it difficult for the people to have access to both rural and urban markets. The major inhabitants of this area are Hausa and Fulani who are predominantly mixed crop-livestock farmers and livestock herders respectively.

\section{Sample size and sampling structure}

A random sampling method was used to determine or measure donkeys, using their metric traits within a given senatorial zone. A total of seven hundred (700) donkeys were used for this study. The weaners, young and adults, males and females were observed and measured in almost equal number. Thirty-three (33) weaners, young and adults, males and females were used in two (2) senatorial zones. Thirty-four (34) donkeys were however, observed in the third senatorial zone to make a total of 100 donkeys to be sampled per State. Donkeys were measured into three age groups (weaners 6 months- 1year, young above 13 years and adults 3 years and above). The age of the donkeys was determined using teeth count (FAO, 2003) in combination with the information provided by the donkey owners.

\section{Data collection}

Weights of the donkeys were measured using prediction equation. Flexible measuring tape was used to take the body measurement. During body measurement, animals were made to stand upright and restrained by assistants in such a way that 
their necks, heads and ears were stretched almost in a straight line. Each measurement was taken for at least two times and recorded to the nearest centimeter. Morphometric traits measures taken were body weight, head length, head width, ear length, neck length, neck circumference, shoulder width, height at withers, heart girth, body length and tail length using random sampling technique.

Reference marks for body measurement according to the method of Searle et al. (1989a and b) and Salako (2006) were as follows:

Body Weight (BWT): This was determine using prediction equation $(\mathrm{kg})$

Head Length (HL): Measured as the distance from between the ears to the upper lip (cm).

Head Width (HWD): Measured as the distance between the outer ends of both eyes $(\mathrm{cm})$.

Ear length (EL): Measured as the distance from the base to the zygomatic arch of the ear $(\mathrm{cm})$.

Neck length (NL): Measured as the distance from the base of the cervical vertebra to the base of the top shoulder $(\mathrm{cm})$.

Neck circumference (NC): Taken as the circumference of the neck at the midpoint (cm).

Shoulder width (SW): Measured as the horizontal distance between the two shoulders or distance between the lateral tuberisities of the humeri which is also described as the widest point over the intraspinus muscle $(\mathrm{cm})$.

Height at Wither (HW): Vertical distance from ground to the point of withers measured vertically from the ridge between the shoulder bones to the fore hoof $(\mathrm{cm})$.

Heart girth (HG): Measured as the circumference of the body at the narrowest point just behind the shoulder perpendicular to the circumference of the body, just in front of the hind leg perpendicular to the body axis $(\mathrm{cm})$.

Body length (BL): Distance between points of shoulder to point of hip i.e the distance from the first thoracic vertebrae to base of tail. This is also described as the distance between the most cranial palpable spinosus process of thoracic vertebrae and either sciatic tubers or distance between the tops of the pelvic bone $(\mathrm{cm})$.

Tail length (TL): Measured from the base of the tail to the tip (cm).

\section{Analysis of variance of morphometric traits}

The effects of sex and age category on body linear measurements were estimated using the GLM procedure of the statistics analysis system SAS (2004) statistical package as shown in the model below.

$\mathrm{Y}_{\mathrm{ijk}}=\mu+\mathrm{S}_{\mathrm{i}}+\mathrm{A}_{\mathrm{j}}+\mathrm{e}_{\mathrm{iik}}$

Where $\mathrm{Y}_{\mathrm{ijk}}$ is the record of observation

$\mu=$ population mean

$\mathrm{S}_{\mathrm{i}}=$ Effect of $\mathrm{i}^{\text {th }}$ sex of donkeys (males and females).

$A_{j}=$ Effect of the $j^{\text {th }}$ age group of donkeys (Weaner, Young and Adults).

$\mathrm{e}_{\mathrm{ijk}}=$ Random error particular to the $\mathrm{ijk}^{\text {th }}$ observation assumed to be independently randomly distributed with mean zero and variance $\operatorname{NIID}(0, \mathrm{e})$.

\section{Regression analysis}

Stepwise regression procedure was used to find the best linear combination of metric variables that can best predict the live weight. This was performed for each sex and age category of donkey. The following linear multiple regression models were applied.

$$
\begin{aligned}
& Y=a+b_{1} X_{1}+b_{2} X_{2}+b_{3} X_{3} \\
& +\ldots \ldots b_{i} X_{i} \\
& \text { Where: } \\
& Y=\text { the dependent variable (Live } \\
& \text { weight) } \\
& a=\text { the intercept of regression } \\
& \text { curve on } y-\text { axis and is the value of }
\end{aligned}
$$


the dependent variable y when all independent variables are Zero.

$\mathrm{b}_{1}=$ the partial regression coefficient associated with respective independent variable $\mathrm{X}_{1}$.

$\mathrm{X}_{1}=$ the independent variables (i.e. body measurement) the regression assumes that the

Independent variable has no measurement error.

And that the above errors about the regression line are equal. The regression analysis was carried out using the REG procedure of R 2.13.0 (R Development Core Team, 2015) package. Comparison of regression equations were based on coefficient of determination $\left(\mathrm{R}^{2}\right)$.

\section{Correlation analysis}

The degrees of association between all pairs of metric variables were computed for all the donkeys within each groups using CORR procedure of SAS (2004) statistical package. This was done to evaluate changing magnitude of association among variables.

Correlation coefficients were estimated according to this formular:

Phenotypic correlation ( $\mathrm{rP}$ )

$$
\gamma_{A_{1} A_{2}}=\frac{\sigma A_{1} A_{2}}{\sqrt{\sigma^{2} A_{1} \sigma^{2} A_{2}}}
$$

Where $\sigma_{A 1 A 2}$ is the covariate between traits $A_{1}$ and $A_{2}$ and $\sigma_{A 1}{ }^{2}$ and $\sigma_{A 2}{ }^{2}$ are variance for traits $A_{1}$ and $A_{2}$, respectively.

\section{Results and discussion}

The stepwise regression analyses for the best linear combinations of metric variables for predicting live body weight of donkeys are presented in Table 1 . The predictors significantly $(\mathrm{p}<0.01)$ predicted body weight of these donkeys with good efficiencies $\left(\mathrm{R}^{2}=67-100 \%\right)$. The prediction of body weight of Nigeria donkeys based on sex and age categories revealed that the combination of NC and TL were the best predictors of body weight (BWT) in male weaner donkeys $\left(R^{2}=100 \%\right)$. The best predictors of body weight in female weaners was body length (BL) with the $\left(\mathrm{R}^{2}\right.$ $=100$ ). The head width (HWD), neck length (NL), neck circumference (NC), and height at withers $(\mathrm{HW})\left(\mathrm{R}^{2}=100\right)$ were the best predictors of BWT in male young donkeys and heart girth in females $\left(\mathrm{R}^{2}=100\right)$. The best predictors in male adult donkeys were $\mathrm{NC}$ and $\mathrm{BL}\left(\mathrm{R}^{2}=100\right)$. For female adults, height at withers (HW) and heart girth were the best predictors of BWT $\left(\mathrm{R}^{2}=100 \%\right)$. Tail length (TL) featured more prominently in the prediction of body weight male and female weaners; height at wither (HW) and neck circumference for male young; and heart girth for female young. Body length featured more prominently for male adults and height at withers for female adults. The result of this study is similar with the report of (Pearson and Oussat, 1996) who reported that the prediction equation containing two or more variables gave a reasonable degree of prediction than an equation with one variable.

Sex differentiated correlation coefficients between morphometric traits of adults donkeys are reflected in Table 2. In the male differentiated relationships, body weight was not significantly $(\mathrm{p}>0.05)$ correlated with body dimension measures $(\mathrm{r}=-0.002$ to 0.09 ), except between body weight and tail length $(\mathrm{p}<0.01 ; \mathrm{r}=0.43)$. In females, body weight relationships with body dimension measures were significantly positive and low to high in magnitude $(\mathrm{p}<0.05,0.01$; $\mathrm{r}=0.18-0.98)$ with height at withers exhibiting the single high relationship of $98 \%$. In the males and females, the body dimension measures were positively and significantly correlated among themselves 


\section{John and Iyiola-Tunji}

Table 1: Stepwise regression analysis for the best linear combination of metric

\begin{tabular}{|c|c|c|c|}
\hline $\begin{array}{l}\text { Sex/Age } \\
\text { categories }\end{array}$ & Predictor & Prediction equation & $\mathbf{R}^{2}$ \\
\hline Male weaner & $\begin{array}{l}\text { TL } \\
\text { NC TL }\end{array}$ & $\begin{array}{l}\square 28.204+3.69 \mathrm{TL} \\
\square 5.0991+(\square 0.73 \mathrm{NC})+3.81 \mathrm{TL}\end{array}$ & $\begin{array}{l}0.99 * * \\
1.00^{* *}\end{array}$ \\
\hline Female weaner & BL & $\square 167.75+2.75 \mathrm{BL}$ & $1.00 * *$ \\
\hline Male young & $\begin{array}{l}\text { HW } \\
\text { NC HW } \\
\text { HWD NC HW } \\
\text { HWD NLNC HW }\end{array}$ & $\begin{array}{l}\square 112.05+2.24 \mathrm{HW} \\
\square 113.75+1.11 \mathrm{NC}+1.60 \mathrm{HW} \\
\square 117.92+2.65 \mathrm{HWD}+1.09 \mathrm{NC}+1.28 \mathrm{HW} \\
\square 130.92+2.58 \mathrm{HWD}+0.56 \mathrm{NL}+0.99 \mathrm{NC}+1.24 \mathrm{HW}\end{array}$ & $\begin{array}{l}0.67 * * \\
0.89^{* * *} \\
0.97 * * \\
1.00^{* *}\end{array}$ \\
\hline Female young & HG & $\square 204.73+3.06 \mathrm{HG}$ & $1.00 * *$ \\
\hline Male adult & $\begin{array}{l}\mathrm{BL} \\
\mathrm{NC} B \mathrm{BL}\end{array}$ & $\begin{array}{l}\square 249.59+3.64 \mathrm{BL} \\
\square 242.92+(\square 0.58 \mathrm{NC})+3.92 \mathrm{BL}\end{array}$ & $\begin{array}{l}0.97 * * \\
1.00^{* * *}\end{array}$ \\
\hline Female adult & $\begin{array}{l}\text { HW } \\
\text { HW HG }\end{array}$ & $\begin{array}{l}\square 46.997+1.78 \mathrm{HW} \\
\square 256.33+1.77 \mathrm{HW}+1.88 \mathrm{HG}\end{array}$ & $\begin{array}{l}0.99 * * \\
1.00 * *\end{array}$ \\
\hline
\end{tabular}

$(\mathrm{p}<0.05,0.01 ; \mathrm{r}=0.11-0.88)$. However, there was non-significant ( $\mathrm{p}>0.05)$ positive correlation between tail length and height at withers $(\mathrm{r}=0.07)$ in the males; and height at withers and shoulder width $(r=0.06)$ in the females. The recurring negative associations between BWT and SW (0.04), SW and HW (-0.04), HW and BL ($0.01)$ in adult donkeys were at variance with literature reports of Martina et al. (2015) who reported positive correlation in all the values, suggesting that if one value rises, other values will do the same. Negative correlation among the body weight and body linear measurement have been found in this study, which is in agreement with the findings of Folch and Jordana (1997) who reported negative relationships among some biometric traits of donkeys. The negative and nonsignificant coefficient of relationships among other biometric traits observed in adult donkeys might be because of the increased in age. This implies that bodyweight had no or less relationship with body linear measurements.

The tail shape differentiated correlations between the morphometric traits of donkeys is presented in Table 3. The observed relationships were significant $(\mathrm{p}<0.05,0.01)$ and positive $(\mathrm{r}=0.11-0.89)$ in both high-set and pendent tail shapes; except for non-significant cases for tail shape, body weight and shoulder width $(\mathrm{r}=0.03)$; height at withers with neck length, neck circumference and shoulder width $(\mathrm{r}=0.01-0.09)$ in the high-set; and tail length and height at withers $(\mathrm{r}=0.08)$ in the pendent tail shape. Generally, the relationship is stronger in the pendent than in the high-set tail shapes. The result of this study is similar to the findings of (John et al., 2017) who reported low, moderate to high relationships between body weight and body linear measurements in donkeys. Several studies reported a strong correlation between some body linear sizes with some production traits, that is, body linear size can be used to estimate the body weight of sheep (Abdel-Moneim, 2009) and goats (Adeyinka and Muhammed, 2006). The results of this study are similar to the findings of (Assan, 2015) who reported positive correlation between body weight and body linear measurement in three pig genotype. 


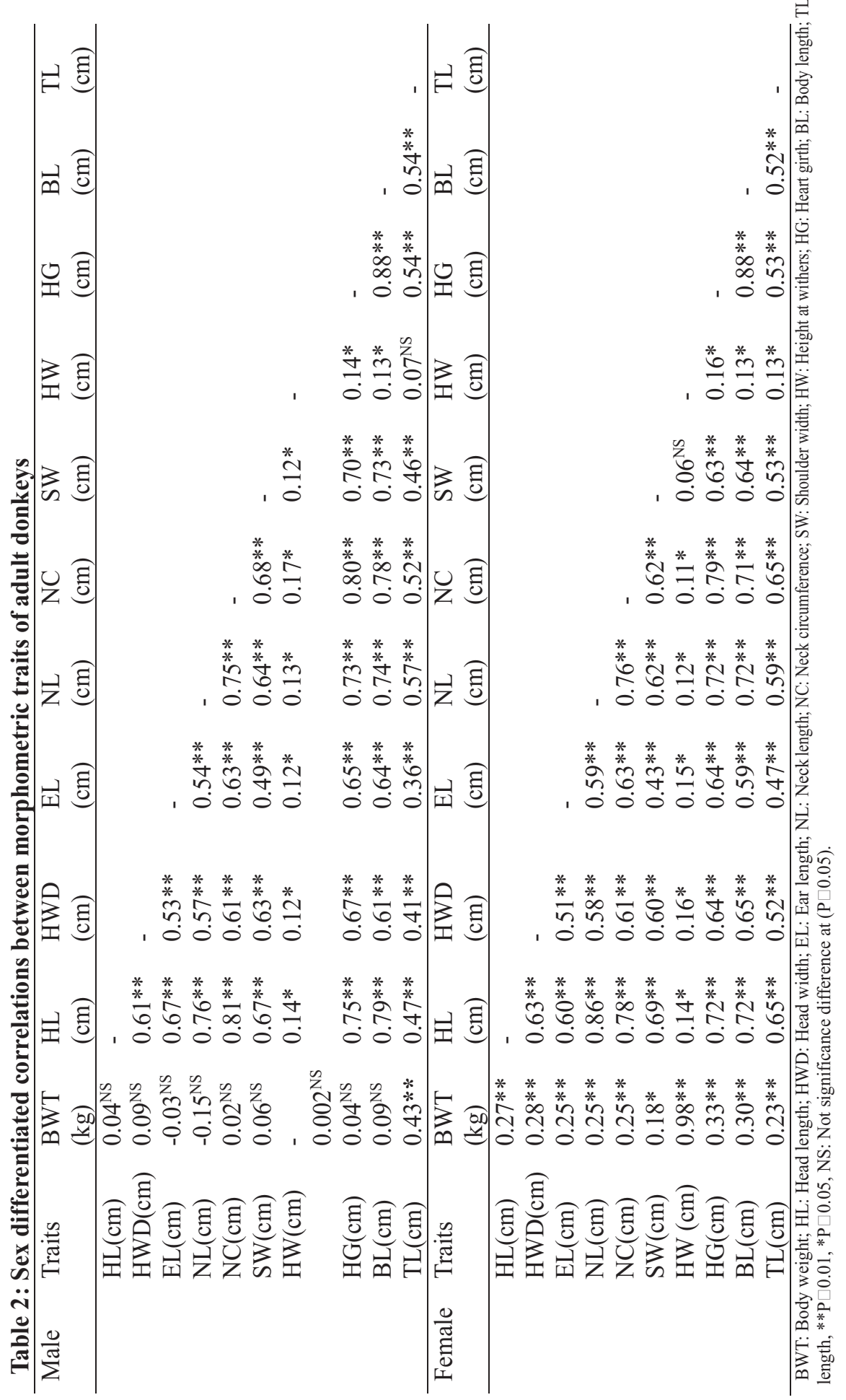




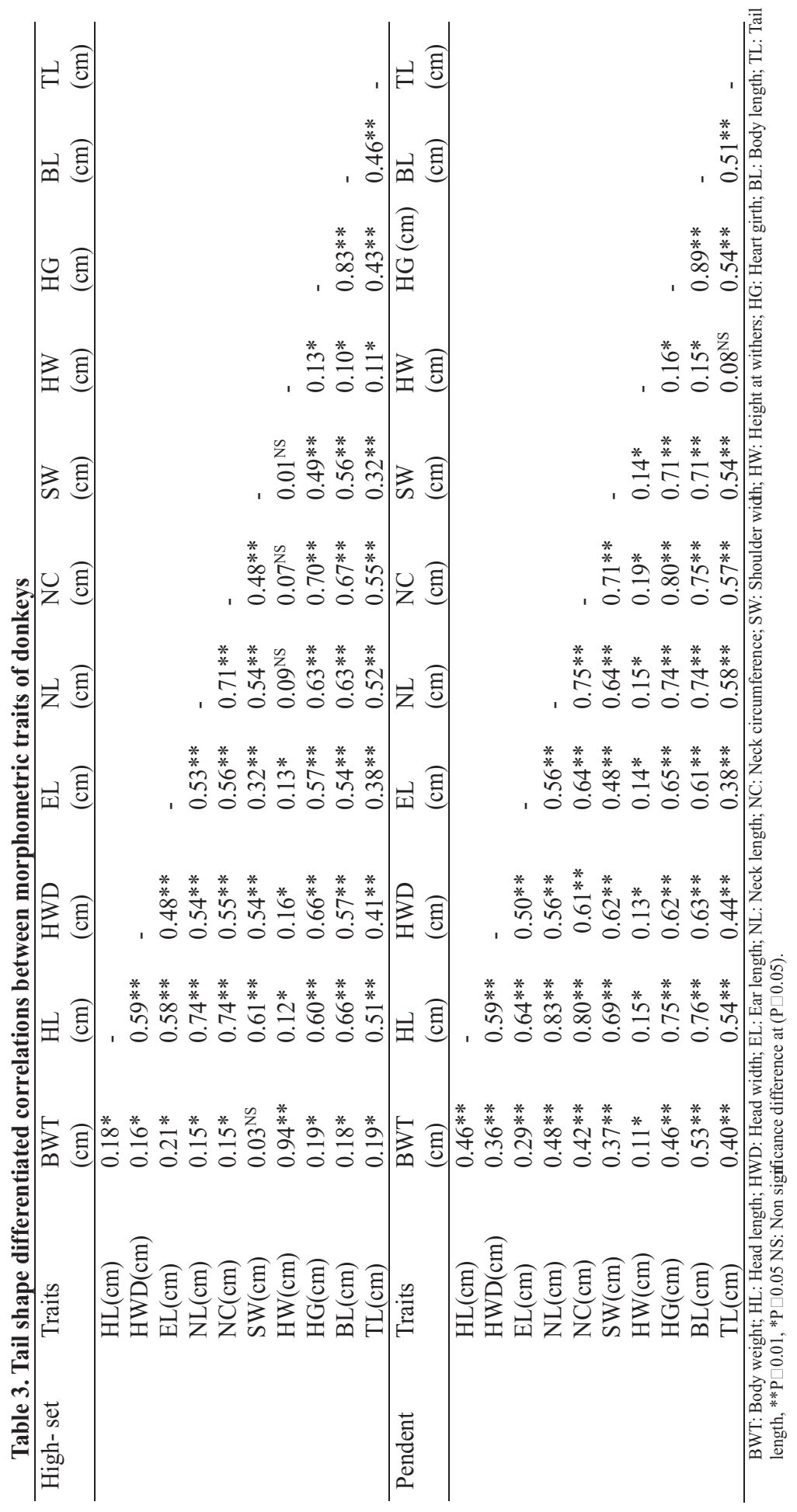


The correlated relationships between morphometric traits of donkeys are indicated in Table 4. The traits were significantly $(\mathrm{p}<0.05,0.01)$ and positively correlated amongst themselves $(r=0.09$ 0.87). The magnitude of correlations between body weight and body dimensions were low ( $\mathrm{r}=0.13-0.23)$ except that between body weight and height at withers which was high $(\mathrm{r}=0.68)$. However, height at withers had low correlations $(\mathrm{r}=0.09-0.14)$ with other body dimensions. Other body dimensions had moderate to high positive correlations amongst themselves $(\mathrm{r}=0.41$ 0.87 ) except for low relationships between ear length and head length $(\mathrm{r}=0.13)$. The correlated relationships within the morphometric traits of donkeys were low, moderate and high. The result of this study is similar with the findings of Yilmaz and Ertugrul (2011) and Martina et al. (2015) who reported high and positive values for correlation between body weight and body linear measurements in donkeys.

Table 4: Correlated relationships between morphometric traits of donkeys

\begin{tabular}{|c|c|c|c|c|c|c|c|c|c|c|}
\hline Traits & $\begin{array}{l}\text { BWT } \\
(\mathrm{kg})\end{array}$ & $\begin{array}{l}\text { HL } \\
(\mathrm{cm})\end{array}$ & $\begin{array}{l}\text { HWD } \\
(\mathrm{cm})\end{array}$ & $\begin{array}{l}\text { EL } \\
(\mathrm{cm})\end{array}$ & $\begin{array}{l}\text { NL } \\
(\mathrm{cm})\end{array}$ & $\begin{array}{l}\mathrm{NC} \\
(\mathrm{cm})\end{array}$ & $\begin{array}{l}\text { SW } \\
(\mathrm{cm})\end{array}$ & $\begin{array}{l}\text { HW } \\
(\mathrm{cm})\end{array}$ & $\begin{array}{l}\mathrm{HG} \\
(\mathrm{cm})\end{array}$ & $\begin{array}{l}\mathrm{BL} \\
(\mathrm{cm})\end{array}$ \\
\hline $\mathrm{HL}(\mathrm{cm})$ & $0.19 * *$ & - & & & & & & & & \\
\hline $\mathrm{HWD}(\mathrm{cm})$ & $0.20 * *$ & $0.61 * *$ & - & & & & & & & \\
\hline $\mathrm{EL}(\mathrm{cm})$ & $0.16 * *$ & $0.13 *$ & $0.52 * *$ & - & & & & & & \\
\hline $\mathrm{NL}(\mathrm{cm})$ & $0.18 * *$ & $0.72 * *$ & $0.46 * *$ & $0.57 * *$ & - & & & & & \\
\hline $\mathrm{NC}(\mathrm{cm})$ & $0.17 * *$ & $0.78 * *$ & $0.61 * *$ & $0.63 * *$ & $0.75 * *$ & - & & & & \\
\hline $\mathrm{SW}(\mathrm{cm})$ & $0.13^{*}$ & $0.67 * *$ & $0.67 * *$ & $0.45 * *$ & $0.62 * *$ & $0.64 * *$ & - & & & \\
\hline $\mathrm{HW}(\mathrm{cm})$ & $0.68 * *$ & $0.13^{*}$ & $0.14 *$ & $0.13^{*}$ & $0.12 *$ & $0.13^{*}$ & $0.09 *$ & - & & \\
\hline $\mathrm{HG}(\mathrm{cm})$ & $0.22 * *$ & $0.72 * *$ & $0.65 * *$ & $0.64 * *$ & $0.72 * *$ & $0.78 * *$ & $0.65 * *$ & $0.14 *$ & - & \\
\hline $\mathrm{BL}(\mathrm{cm})$ & $0.22 * *$ & $0.74 * *$ & $0.63 * *$ & $0.60 * *$ & $0.72 * *$ & $0.73 * *$ & $0.67 * *$ & $0.13 *$ & $0.87 * *$ & - \\
\hline $\mathrm{TL}(\mathrm{cm})$ & $0.23 * *$ & $0.56 * *$ & $0.46 * *$ & $0.41 * *$ & $0.58 * *$ & $0.58 * *$ & $0.49 * *$ & $0.10 *$ & $0.53 * *$ & $0.51 * *$ \\
\hline
\end{tabular}

\section{Conclusion}

The study showed that the Body weight of donkeys across age groups and sexes can be predicted using tail length in male and female weaner donkeys, height at withers and heart girth in male and female young donkeys, body length and height at withers in male and female adult donkeys. The correlated relationships were significantly and positively correlated between body weight and other body linear measurements of donkeys in Northwest Nigeria with exception of some biometric traits in young and male adult donkeys, which showed negative and non-significant coefficient of association among some biometric traits of donkeys.

Further studies can be carried out in order to determine association and relationships between body weight and body linear measurements.

\section{Acknowledgement}

The authors thank to late Prof. G.N. Akpa for his tireless effort in making this work a success.

\section{References}

Abdel-Moneim, A. Y. 2009. Use of live body measurements for prediction of body and carcass cuts weights in three Egyptian breeds of sheep. Egyptian. Journal of Sheep and Goat Science, 2: 17-32.

Adeyinka, I. A. and Mohammed, I. D. 2006. Relationship of liveweight and linear body measurement in two breeds of goat of Northern 
Nigeria. Journal of Animal Veterinary Advances, 5: 891-893.

Assan, N. 2015. Prospects for utilization of the relationship between zoometrical measurements and performance traits for poultry and livestock genetic improvement in developing countries.Scientific Journal of Animal Science, 4(11): 124-132.

Bartholemew, P. W., Thibe, T. and Little, D. A. 1993. Effect of change in body weight and condition during the dry season on capacity for work of draft oxen. Tropical Animal Health Production 25: 50-58.

Eley, J. L. and French, J. M. 1993. Estimation of the live weight and body condition of working donkeys in Morocco. Veterinary Record 132, 250.

Fajemilehin, O. K. S. and Salako, A. E. 2008. Body measurement characteristics of the West African Dwarf (WAD) goat in deciduous forest zone of Southwestern Nigeria. African Journal of Biotechnology, 7: 2521-2526.

Folch, P. and Jordana, J. 1997. Characterization, reference ranges and the influence of gender on morphological parameters of the endangered Catalonian donkey breed. Journal of Equine Veterinary Science, 17(2): 102111.

Food and Agriculture Organization (FAO). 2003. F.A.O Statistical data base webside. Food and Agriculture Organization, Rome, I t a $1 \mathrm{y} \quad(\mathrm{F} \mathrm{A} \mathrm{O} \mathrm{S} \mathrm{t}$ a $\mathrm{t} \mathrm{s}$ : http://apps.fao.org)

John, P. A., Akpa, G. N. and Iyiola-Tunji,
A. O. 2017. Characterization of Young Donkeys in North West Nigeria using Morphometric Traits. Nigerian Journal of Animal Science, 19(1): 1-12

Martina, K., Hana, C., Iveta, B., Ivana, O., Eva, B. and Iva, J. 2015. Characteristics of Morphological Parameters of Donkeys in the Czech Republic. Acta Universitatis Agriculturae et Silviculturae Mendelianae Brunensis, 63 (2): 419-424.

Mekonnen, H. M. and Biruk, T. 2004. Heart girth-body weight relationship in two Ethiopian zebu breeds. Revue de Medecine Veterinaire, 155: 512-515.

NPC, 2006. National Population Commission, Abuja, Nigeria. www. Nigeriannews.com/census /census2006.htm (Accessed on $25^{\text {th }}$ January, 2016).

Ogungbile, A. O., Tabo, R., VanDuivenbooden, N. and Debrah, S. K. 1998. Analysis of constraints to agricultural production in the Sudan Savanna Zone of Nigeria using multi-scale characterization. Nigerian Journal of Animal Science 590, 1998.

Oke, U. K. and Ogbonnaya, E. O. 2011. Application of physical body traits in the assessment of breed and performance of WAD sheep in a humid tropical environment. Livestock Resource Rural Development, 23(24).

Pearson, R. A. and Ouassat, M. 1996. Estimation of weight and a body condition scoring system for working donkeys in Morocco. Veterinary Record 138: 229-233. 
R Development Core Team. 2015. $A$ Language and Environment for Statistical Computing. R Foundation For Statistical Computing, Vienna, Austria.URL http://Www. R-Project.org/.

Salako, A. E. 2006. Application of morphological indices in the Assessment of Type and Function in Sheep.International morphology 24.13-18.

SAS, 2004. SAS/STAT user guide: Statistics, Version 8.1, SAS. Institute Inc; Cary, Nc

Searle, T. M., McGraham, N. and Donnely, J. B. 1989a. Change of Skeletal Dimensions During growth in Sheep: The effect of Nutrition. Journal of Agricultural Science, 112:321-327.
Searle, T. M., McGraham, N., Donnely, J. $B$ and Makgari, D. E. $1989 \mathrm{~b}$. Breed and Sex Differences in Skeletal Dimentions of Sheep in the first year of Life. Journal of Agricultural Science, 113:349-354.

Yilmaz, O. and Ertugrul, M. 2011. Some Morphological Traits of Donkeys Raised in Igdir, Turkey. Arastirma.Makalesi/ Research Article.Igdir University Journal of Institute of Science and Technology. 1 (2): 113-116.

Younas, U., Abdullah, M., Bhatti, J. A., Pasha, T. N., Ahmad, N., Nasir, M. and Hussain, A. 2013. Interrelationship of body weight with linear body measurements in Hissardale sheep at different stages of life. Journal of Animal and Plant Science, 23(1), 40-44.

Received: $10^{\text {th }}$ September, 2018 Accepted: $21^{\text {st }}$ December, 2018 